\title{
The Rest Repression of the Neurosecretory Phenotype Is Negatively Modulated by BHC80, a Protein of the BRAF/ HDAC Complex
}

\author{
Andrijana Klajn, ${ }^{2,3,4,5}$ Carmelo Ferrai, ${ }^{1,3}$ Laura Stucchi, ${ }^{2,3}$ Ilaria Prada, ${ }^{2,3}$ Paola Podini, ${ }^{2,3}$ Tadashi Baba, ${ }^{6}$ \\ Mariano Rocchi, ${ }^{7}$ Jacopo Meldolesi, ${ }^{2,3,4,5}$ and Rosalba D'Alessandro ${ }^{2,3,4,5}$ \\ Departments of ${ }^{1}$ Molecular Biology and Functional Genomics and ${ }^{2}$ Neuroscience, ${ }^{3}$ Vita-Salute San Raffaele University and San Raffaele Institute, ${ }^{4}$ National Institute \\ of Neuroscience and ${ }^{5}$ Research Unit of Molecular Neuroscience, The Italian Institute of Technology Network, 20132 Milan, Italy, ${ }^{6}$ Institute of Applied Biochemistry, \\ University of Tsukuba, 305-8527 Ibaraki, Japan, and 7Department of Genetics and Microbiology, University of Bari, 70125 Bari, Italy
}

Expression of neurosecretion by nerve cells requires the levels of the transcription repressor element-1 silencing transcription factor (REST) to be very low. However, when high-REST clones of PC12 cells, defective of neurosecretion, were fused to other high-REST, non-neurosecretory cells, some neurosecretion was recovered. To clarify the mechanism of this recovery, we fused defective PC12 cells with human lymphocytes. A cytogenetic analysis revealed all hybrid clones that recovered neurosecretion to contain a fragment of chromosome 11 including the gene encoding BHC80, a protein of one of the complexes that mediate REST repression. In these clones, REST levels were as high as in defective PC12, whereas BHC80, localized in the nucleus, was 4- to 5-fold higher. Transient transfection of defective PC12 with various amounts of BHC80 cDNA induced (1) in defective PC12, the reexpression of only neurosecretion mRNAs; (2) in defective PC12 cotransfected with the REST negative construct DNA-binding domain (to attenuate gene repression), the recovery of a weak, but complete neurosecretory phenotype, including dense-core granules and their regulated exocytosis. Chromatin immunoprecipitation and immunodepletion analyses revealed the extensive BHC80 association with REST at the genes of two neurosecretion proteins, chromograninB and SNAP25, however only in the low-REST PC12, whereas in high-REST defective PC12 no association was appreciable. In defective PC12 transfected with BHC80 some association was reestablished. Therefore, the recovery of neurosecretion observed after fusion/transfection of defective PC12 depends on the reciprocal level of BHC80 and REST, with BHC80 working as a negative modulator of REST repression. This role appears of possible cell physiological and pathological importance.

\section{Introduction}

The hypothesis that differentiation of neural progenitors into neurons and neurosecretory cells is orchestrated by a rapid decline of repressor element-1 silencing transcription factor (REST), raised over 10 years ago (Chong et al., 1995; Schoenherr and Anderson, 1995), has received extensive support and is therefore widely accepted (Ballas and Mandel, 2005; Wu and Xie, 2006). In silico and DNA studies reveled in the genome of many species hundreds of genes, including in their promoter (and/or other regulatory sites) the conserved, $21-23$ bp repressor element-1 (RE-1) sequence, specific for REST binding (Bruce et

Received Dec. 15, 2008; revised Feb. 16, 2009; accepted Feb. 24, 2009.

This work was supported by grants from Italian National Research Council (02.00152.ST97) and Italian Ministry of Research (FIRB 2003-RBLA03AF28 and PRIN 2006). We are grateful to E. Battaglioli for suggestions and assistance; to P. Rosa, M. Solimena, F. Blasi for the gift of antibodies; to N. J. Buckley for the DBD-REST construct; to 0. Cremona and L. Bernard for the qPCR assays; to G. Racchetti for help in some experiments; and to F. Floriani for secretarial assistance.

Correspondence should be addressed to Jacopo Meldolesi, Vita-Salute San Raffaele University, DIBIT, via Olgettina 58, 20132 Milan, Italy. E-mail: meldolesi.jacopo@hsr.it.

A. Klajn's present address: Institute of Molecular Genetics and Genetic Engineering, 11010 Belgrade, Serbia.

C. Ferrai's present address: MRC Clinical Sciences Centre, Imperial College School of Medicine, Hammersmith Hospital Campus, London W120NN, UK.

DOI:10.1523/JNEUROSCI.5943-08.2009

Copyright $\odot 2009$ Society for Neuroscience $\quad$ 0270-6474/09/296296-12\$15.00/0 al., 2004; Mortazavi et al., 2006; Johnson et al., 2007; Otto et al., 2007). In high REST, non-nerve cells, most RE-1 genes are RESTbound and repressed (Otto et al., 2007), whereas after nerve cell differentiation many of them are turned into expression (Sun et al., 2005). Recently, however, REST was shown to be important also in mature nerve cells. Heterogeneous expression of their proteins was noticed among neurons (Sun et al., 2005), whereas changes induced by pathological events were shown to contribute to cytotoxicity (Calderone et al., 2003; Spencer et al., 2006; Formisano et al., 2007). REST appears therefore to participate in the control of gene expression throughout the whole life of nerve cells.

The rat pheochromocytoma PC12 line was instrumental to reveal the role of REST in regulating the expression of the neurosecretory phenotype. Transfection of PC12 cells with full-length REST resulted in the downregulation of many genes of neurosecretory vesicles and of their exocytosis (neurosecretion genes) (Bruce et al., 2006; D’Alessandro et al., 2008). Conversely, transfection of a dominant-negative construct of REST in defective PC12 clones, expressing high REST and lacking neurosecretion, induced some recovery of the process (Pance et al., 2006; D'Alessandro et al., 2008). Recovery of typical neurosecretory organelles, the dense-core vesicles (DCVs), was also reported in hybrid clones produced by the fusion of the same defective cells 
with other cell types, neurosecretory (low REST) and even nonneurosecretory (high REST) (Borgonovo et al., 1998; Malosio et al., 1999). Whether these results were caused by decreases of REST or by changes of its function, was unknown.

This problem has now been investigated, by cytogenetic, gene expression, and cell biology techniques, in defective PC12/human (h-) lymphocyte hybrids. The results demonstrated a partial recovery of neurosecretion in a number of high REST hybrid clones, and identified BHC80 (also known as PHF21A), a member of BHC [core-BRCA2-associated factor (BRAF)-histone deacetylase (HDAC), a repressive complex associated to the C-terminal domain of REST], as a factor sufficient for such recovery to occur. BHC80 is differentially expressed in various cells and tissues (high in brain, low in many peripheral organs). Its role was still debated (Hakimi et al., 2002; Iwase et al., 2004; Shi et al., 2005; Lan et al., 2007). Our data, obtained with defective PC12 transfected or not with $\mathrm{BHC} 80$, demonstrate that association with BHC80 modulates negatively the repressor activity of REST and can thus contribute to the recovery of the neurosecretory competence of the cells.

\section{Materials and Methods}

Most materials and procedures used were as in the study by D'Alessandro et al. (2008).

Monoclonal and polyclonal antibodies, and chemicals. The IgG2a ratspecific chromograninB ( $\mathrm{ChgB}$ ) monoclonal antibody ( $\mathrm{mAb}$; generated in the Milan laboratory) was as in the study by Borgonovo et al. (2002); the anti-BHC80 polyclonal antibody (pAb; generated in the Ibaraki laboratory), as in the study by Iwase et al. (2004). The anti-ICA512 mAb, the anti-secretogranin $2(\mathrm{Scg} 2) \mathrm{pAb}$, and the anti-uPAR pAb were the gifts of M. Solimena (University of Dresden, Dresden, Germany), P. Rosa (Consiglio Nazionale delle Ricerche Institute of Neuroscience, Milan, Italy), and F. Blasi (San Raffaele Institute, Milan, Italy), respectively. Other Abs were from commercial sources: anti-REST and anti-H2B pAbs: Upstate Cell Signaling; anti-synaptotagmin 1 (Syt1), anti-synaptophysin1 (Syp1), anti-Rab3a, anti-VAMP2, and anti-ß-tubulin mAbs: Synaptic Systems; anti-SNAP25 mAb: Sternberger-Monoclonal; anti-syntaxin1a (Stxla) $\mathrm{mAb}$ and anti-flag pAb: Sigma-Aldrich; anti-green fluorescent protein (GFP) mAb: Roche; anti-GAPDH mAb: AbD Serotec; anti-hCD19 and anti-hCD2 mAbs: BD PharmMingen; FITC-conjugated and tetramethylrhodamine isothiocyanate-conjugated goat anti-mouse and anti-rabbit pAbs and goat anti-mouse IgG subclasses: Southern Biotech; horseradish peroxidase-conjugated goat anti-mouse and anti-rabbit pAbs: Bio-Rad; and immunogold particles ( 6 or $10 \mathrm{~nm}$, coated with anti-mouse IgGs): BioCell. The fluorescent DNA-binding probe, 4,6-diamidino-2phenylindole-dihydrochroride (DAPI) and cycloheximide were from Sigma-Aldrich; the BCA Protein Assay Kit, from Pierce. All other chemicals were from Sigma-Aldrich.

Cell clones and cell fusions. The wild-type (wt) PC12 and PC12-27 clones were as in the study by Borgonovo et al. (2002); the PC12-Trk clone, as in the study by Leoni et al. (1999); the PC12-27 subclone stably transfected with DNA-binding domain (DBD)-REST (gift from N. Buckley, London, UK) (PC12-27/DBD clone), as in the study by D'Alessandro et al. (2008); the INS-1E cells, as in the study by Merglen et al. (2004); the rat skeletal L6E9 myoblasts, as in the study by Kaliman et al. (1998).

Wt PC12, the defective PC12-Trk and PC12-27 clones and their subclones were grown at $37^{\circ} \mathrm{C}$ as in the study by Cocucci et al. (2004). To generate hybrids, human lymphocytes (h-lymphocytes; from volunteers) were mixed (3:1) with defective PC12 (PC12-Trk and PC12-27), resuspended in DMEM, fused with $50 \%$ polyethylenglycol as in the study by Borgonovo et al. (2002), and plated overnight. After removal of the nonattached cells, fused and nonfused PC12 were resuspended and exposed to fluorescent anti-hCD19 and anti-hCD2 mAbs, sorted by FACS and cloned in 96 well dishes, 1 cell/well. Positive clones were identified by their neurosecretion marker expression. During culture, marker-positive
Table 1. Primers used for RNA detection

\begin{tabular}{lll}
\hline Primer sets & Primer sequences $\left(5^{\prime}-3^{\prime}\right)$ & Annealing temperature ${ }^{\circ} \mathrm{C}$ \\
\hline Hr-80up & GTGGCCCAGAATAACATTCCTATCGC & 57 \\
Hr-80lw & ACTGTACACCGGGTTTGCTGTTGTTC & 57 \\
RT-GAPDH-F & ACCACAGTCCATGCCATCAC & 57 \\
RT-GAPDH-R & TCCACCACCCTGTGCTGTA & 57 \\
\hline
\end{tabular}

clones were most often unstable. This required systematic reisolation and characterization of subclones.

Transfection of BHC80 cDNAs. BHC80-4-flag and BHC80-6-flag tagged constructs were as in the study by Iwase et al. (2004). The GFP construct was pEGFP-C1 from BD Clontech. The transient transfection procedure was as described by D'Alessandro et al. (2008). In particular, $1 \times 10^{6}$ PC12-27 and PC12-27/DBD cells were treated for $24 \mathrm{~h}$ with Lipofectamine 2000 (Invitrogen) together with $0.07-4 \mu \mathrm{g}$ of the BHC80flag cDNA. When the BHC80-flag cDNA was transfected together with GFP cDNA $\left(4 \mu \mathrm{g} / 3 \times 10^{6}\right.$ cells), the cells positive for the fluorescent protein were sorted out by FACS. The ensuing cell populations are indicated as PC12-27/BHC80-flag and PC12-27/DBD/BHC80-flag.

Fluorescence in situ hybridization and bacterial artificial chromosome mapping. Appropriate bacterial artificial chromosome (BAC) clones were identified on the UCSC genome browser (http://www.genome.ucsc.edu). DNA extraction from BACs was made as reported previously (Ventura et al., 2001). Cohybridization fluorescence in situ hybridization (FISH) experiments on hybrid PC12-Trk/h-lymphocyte and PC12-27/ h-lymphocyte clones were performed essentially as described by Lichter et al. (1990). Digital images were obtained using a Leica DMRXA2 epifluorescence microscope equipped with a cooled charge-coupled device camera (Princeton Instruments). Cy3-dCTP, Fluorescein-dCTP, and DAPI fluorescence signals, detected with specific filters, were recorded separately as gray scale images. Pseudocoloring and merging of images were performed using Adobe Photoshop software.

RNA detection. For quantitative real-time PCR (qPCR) of total (human and rat forms) BHC80 expression levels, total RNA was extracted with RNeasy mini kit (Qiagen), quantified by spectrophotometry, and 1 $\mu \mathrm{g}$ of total RNA was reverse-transcribed using a SuperScript III FirstStrand kit (Invitrogen) according to the manufacturer's instructions. Five nanograms of reverse-transcribed RNA were amplified in a light cycler (Roche) using a FastStart DNA mix SYBR Green I kit (Roche). The amount of BHC80 mRNA was normalized to GAPDH mRNA. Each sample was analyzed in triplicate for both GAPDH and BHC80. Data are presented as mean \pm SD. For the primers used, see Table 1 .

For detection of the human BHC80 expression, RNA was extracted and processed as described previously, and $5 \mathrm{ng}$ were amplified using Taq Gold (Roche). PCR products were analyzed on $2 \%$ agarose gels in 0.5 TBE buffer ( $45 \mathrm{~mm}$ Tris-borate; $1 \mathrm{~mm}$ EDTA, $\mathrm{pH}$ 7). The primer sequences $\left(5^{\prime}-3^{\prime}\right)$ used at $57^{\circ} \mathrm{C}$ annealing temperature were as follows for h-upBHC: GTGGCCCAGAATAACATTCCTATTGC, and for h-lowBHC: GTGCAGCAGGTGGGGTGATGGTG.

For quantitative detection of neurosecretion gene mRNA, RNA was extracted and retrotranscribed as described above. Five nanograms were amplified and products detected using TaqMan gene expression assays (Applied Biosystems) in an ABI PRISM 7900HT Sequence Detection System (Applied Biosystems), using 18S RNA for normalization. Rqmin/ Rqmax indicates the SE (confidence 95\%) (Table 2).

Western blotting. Total cell extracts were prepared as described previously by Xu et al. (2003). In particular, cells were solubilized in lysis buffer containing 1\% Triton X-100, 50 mm Tris-HCl, pH 7.5, $250 \mathrm{~mm}$ $\mathrm{NaCl}, 5 \mathrm{~mm}$ EDTA, $50 \mathrm{~mm} \mathrm{NaF}$, and protease inhibitors. Nuclear and cytoplasmic fractions were separated according to Dignam et al. (1983). Proteins were quantified by BCA assay and appropriate amounts (most often $50 \mu \mathrm{g}$ ) were separated by SDS-PAGE. After transfer to nitrocellulose filters, they were immunolabeled as in the study by Cocucci et al. (2004). Photographic development was by chemiluminescence (ECL, Amersham Bioscience or Immobilon substrate, Millipore). Western blot bands were quantified by the ImageJ program (rsb.info.nih.gov/ij). Data 
Table 2. TaqMan gene expression assays

\begin{tabular}{ll}
\hline Gene symbol & Assay ID \\
\hline ChgB & Rn00560973_m1 \\
Scg2 & Rn02042961_s1 \\
Syt1 & Rn00436862_m1 \\
SNAP25 & Rn00578534_m1 \\
ICA512 & Rn00709739_m1 \\
Rab3a & Rn00564615_m1 \\
VAMP2 & Rn00360268_g1 \\
Stx1a & Rn00587278_m1 \\
18S & 4319413E \\
\hline
\end{tabular}

Table 3. Primers used for ChIP

\begin{tabular}{lll}
\hline Primer sets & Primer sequences $\left(5^{\prime}-3^{\prime}\right)$ of RE-1 regions & $\begin{array}{l}\text { Annealing } \\
\text { temperature }{ }^{\circ} \mathrm{C}\end{array}$ \\
\hline $\begin{array}{l}\text { ForChgB } \\
\text { RevChgB }\end{array}$ & CACCCCGCCTGCCCTTCATAAGAG & \\
For3SNAP25 & TGAACCCGGTACTTGCAGCGCCG & 64 \\
Rev3SNAP25 & AATCATAGGGTTGGAACGAA & 57 \\
For3NSE & GAGCCTCTTTCTTGCTGTCCCGAC & \\
Rev3NSE & CACACACCAATCCTGAAGCTCCTG & 65 \\
\hline
\end{tabular}

presented, expressed as percentage of the corresponding values in wt PC12 cells, are means of at least three experiments \pm SD.

Chromatin immunoprecipitation: chromatin preparation, immunoprecipitation, and PCR. Cross-linked chromatin was prepared as described by Ferrai et al. (2007) from wt PC12, PC12-27, and PC12-27/DBD cells transfected or not with BHC80 cDNA. In brief, cells were cross-linked with $1 \%$ formaldehyde for $10 \mathrm{~min}$ and samples treated with 10 sonication cycles of 35 s (Ultrasonic Processor XL Sonicator, Miosonix, at 60-70 $\mathrm{W})$, each followed by a $2 \mathrm{~min}$ rest on ice. Cross-linked chromatincontaining fractions were pooled and stored at $-80^{\circ} \mathrm{C}$. Aliquots of $200 \mu \mathrm{g}$ of cross-linked chromatin were precleared with $35 \mu \mathrm{l}$ of Protein A-Sepharose-coated beads (Pharmacia) in RIPA buffer. Each of two aliquots was then incubated overnight with $1 \mu \mathrm{g}$ of anti-REST and antiBHC80 Abs, respectively, or without Abs (mock controls), in a total volume of $1 \mathrm{ml}$ of RIPA buffer. Anti-uPAR pAb was used as negative control. After immunoprecipitation, the material was treated with RNaseA $(50 \mu \mathrm{g} / \mathrm{ml})$ for $30 \mathrm{~min}$ at $37^{\circ} \mathrm{C}$, and by proteinase $\mathrm{K}(500 \mu \mathrm{g} / \mathrm{ml})$ in $0.5 \%$ SDS at the same temperature overnight. Cross-links were reverted by heating the samples at $65^{\circ} \mathrm{C}$ for $5 \mathrm{~h}$. The DNA purified and resuspended in $250 \mu \mathrm{l}$ of distilled water, and $4 \mu \mathrm{l}$ were used as template. Chromatin immunoprecipitation (ChIP)-enriched DNAs of indicated amplicons [ChgB, SNAP25, and neuron-specific enolase (NSE)] was quantified by qPCR in a light cycler (Roche) using FastStart DNA mix SYBR Green I kit (Roche). ChIP samples were analyzed in triplicate PCRs. The relative enrichment of genomic DNA is the ratio between the DNAs in the immunoprecipitates and in the input chromatin. The values given, subtracted of the mock, are means of three separate experiments \pm SD (Table 3).

Immunodepletion. After immunoprecipitation with anti-REST and anti-BHC80 Abs, respectively, of the processed chromatin from the various cell populations, as described in the ChIP experiments, the supernatants containing unbound chromatin were precleared for $2 \mathrm{~h}$ with 35 $\mu l$ of previously coated Protein A-Sepharose beads (Pharmacia) and then reimmunoprecipitated by the switched Abs (anti-BHC80 on the antiREST supernatant and anti-REST on the anti BHC80 supernatant), following the procedure described above, as recommended by Hakre et al. (2006).

Immunofluorescence. Experiments were performed as described by Cocucci et al. (2004). Specifically, cell monolayers on coverslips were fixed with $4 \%$ formaldehyde for $10 \mathrm{~min}$ at room temperature (rt) and quenched in $0.1 \mathrm{M}$ glycine, then permeabilized for $20 \mathrm{~min}$ at $\mathrm{rt}$ in PBS containing $0.2 \%$ Triton X-100 and $1 \%$ BSA, and immunolabeled for $1 \mathrm{~h}$ at rt with primary Abs (anti-BHC80, anti-flag, anti-ChgB and anti-Syt1) diluted in PBS with 1\% BSA. Nuclei were stained with DAPI. Samples were studied in Bio-Rad MRC1024 and Perkin-Elmer Ultraview ERS confocal microscopes. Image deconvolution was performed in a wide field microscope of the Delta Vision system (Cocucci et al., 2004).

Exocytic discharge. The turnover of the ChgB-containing organelles was investigated indirectly as in Malosio et al. (2004) and D'Alessandro et al. (2008), by monitoring the levels of the secretory protein in monolayers of wt PC12 cells and of PC12-27/DBD cells transiently transfected with $4 \mu \mathrm{g}$ of BHC80 cDNA. After incubation for various times (up to $6 \mathrm{~h}$ ) in the presence of the protein synthesis blocker, cycloheximide (20 $\mu \mathrm{g} /$ $\mathrm{ml}$ ), the cells were homogenized and analyzed for ChgB content by Western blotting. To investigate ChgB discharge, monolayers of the same cells were resuspended in Krebs-Ringer HEPES (KRH) buffer. Parallel $1.2 \mathrm{ml}$ aliquots were exposed for $15 \mathrm{~min}$ to $1.5 \mu \mathrm{l}$ of either the solvent DMSO or ionomycin in DMSO $(2 \mu \mathrm{M})$. The cells were then recovered by centrifugation and the ChgB content of the pellets was measured as above. The data shown, expressed as percentage of samples exposed to DMSO, are means of 3 experiments \pm SD. To establish whether, in the stimulated cells, ChgB is associated to the cell surface, as it happens for some time after discharge by exocytosis, monolayers exposed to ionomycin for only 2 min were fixed and immunolabeled as described above, however without permeabilization before exposure to the anti-ChgB antibody (Cocucci et al., 2004).

Electron microscopy. Monolayers of PC12-Trk, PC12-27, and of their hybrid clones with h-lymphocytes were fixed with $2 \%$ glutaraldehyde in PBS buffer, washed, postfixed in $2 \% \mathrm{OsO}_{4}$ in PBS buffer, and embedded in Epon. For immunogold labeling, monolayers were fixed with a $4 \%$ formaldehyde $/ 0.25 \%$ glutaraldehyde mixture in PBS buffer, washed, detached and recovered by centrifugation. Extensively washed pellets were embedded in London Resin (LR) white. Ultrathin sections on nickel grids were exposed to the anti-ChgB, anti-Syt1, or control mAbs in phosphate-glycine buffer (90 min), washed, and immunolabeled with gold particles ( 6 or $10 \mathrm{~nm}$, coated with anti-mouse IgGs), washed, postfixed with $1 \%$ glutaraldehyde, and finally stained in sequence with uranyl acetate and lead citrate. Ultrathin sections ( $\sim 60 \mathrm{~nm}$ thick) were studied and photographed in a Leo 912 electron microscope.

\section{Results \\ Recovery of neurosecretion markers in defective PC12/h-lymphocyte hybrids}

Our first task was the generation, by fusion of defective PC12 cells, of hybrid clones exhibiting recovery of neurosecretion (Borgonovo et al., 1998; Malosio et al., 1999), to be used for a cytogenetic search of the genes involved. For this task we used the two defective PC12 clones available in our laboratory, PC12-Trk (Leoni et al., 1999) and PC12-27 (Borgonovo et al., 1998), fused to h-lymphocytes. The isolated hybrid clones were classified as positive or negative based on their expression or lack of expression of two DCV markers: the secretory protein ChgB, recognized by our rat-specific $\mathrm{mAb}$, and the membrane protein Syt1.

Figure $1 A-F$ compares by immunofluorescence the expression of the two markers, ChgB and Syt1, in DAPI-stained clones of PC12, wt, the defective PC12-Trk, and a positive PC12-Trk/hlymphocyte hybrid. The two markers appeared prominent in all wt PC12 cells (Fig. $1 A, D$ ) and completely absent in the defective clone (Fig. 1 B,E) (Malosio et al., 1999; Leoni et al., 1999; Grundschober et al., 2002). In the hybrid clone the results were intermediate, i.e., only a fraction of the cells appeared clearly positive, although less strongly than the wt cells, for both the rat ChgB and the Syt1, whereas some appeared only weakly positive and many completely negative (see Fig. 1C,F for the PC12-Trk/hlymphocyte F5c clone). Results similar to those of Figure 1, $C$ and $F$, were obtained with other 25 positive hybrid clones, including a few generated with the other defective clone, PC12-27. In contrast, 52 additional hybrid clones were completely negative (data 
ChgB
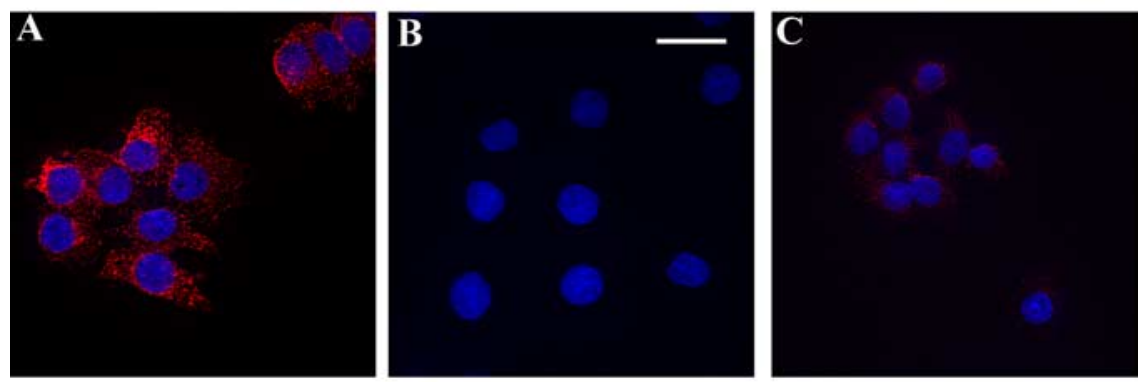

Syt1
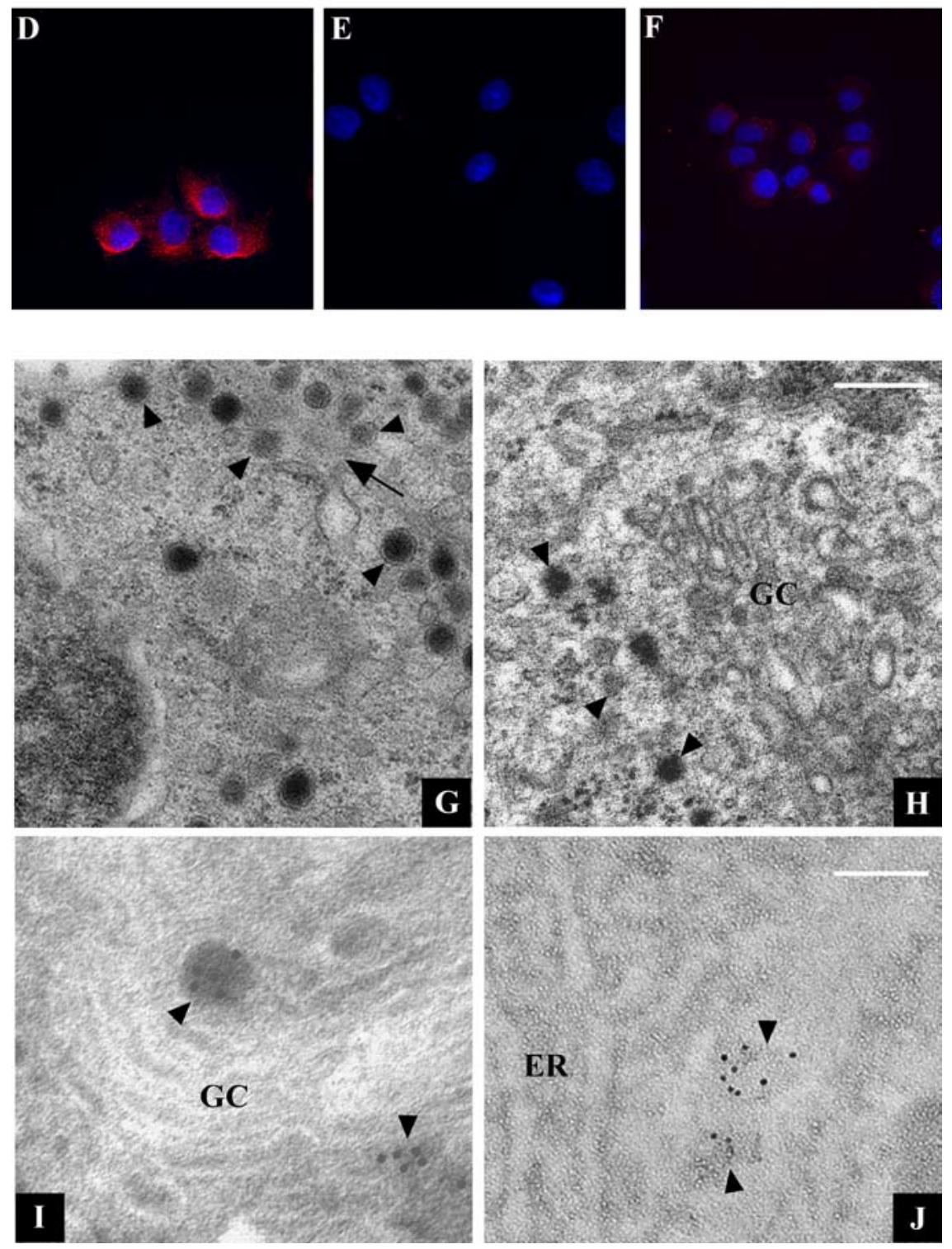

Figure 1. Expression of neurosecretion markers and DCV-like organelles in defective PC12/h-lymphocyte hybrids. $\boldsymbol{A}-\boldsymbol{F}$, The expression of the two neurosecretion markers, $C h g B$ and Syt1, revealed by confocal immunofluorescence in DAPI-stained wt $P(12$ $(\boldsymbol{A}, \boldsymbol{D})$, defective PC12-Trk $(\boldsymbol{B}, \boldsymbol{E})$, and the neurosecretion marker-positive PC12-Trk/h-lymphocyte hybrid clone F5c $(\boldsymbol{C}, \boldsymbol{F})$. G, The ultrastructure of two adjacent wt PC12 cells exhibiting numerous DCVs (arrowheads) preferentially aligned along the plasma membrane profile (arrow); $\boldsymbol{H}$, the Golgi area $(\mathrm{GC})$ of a hybrid cell of the F5c clone, with several DCV-like organelles of various density (arrowheads) clustered in the neighboring cytoplasm. I, J, The anti-rat ChgB and anti-Syt 1 immunogold labeling, respectively, of discrete DCV-like vesicles of various density (arrowheads) in cells of the F5c hybrid clone. Notice that the gold particles of $\mathrm{ChgB}$, a secretory protein, are concentrated over the cores of two vesicles in the Golgi area, whereas those of Syt1, a membrane protein, are mostly aligned around vesicles surrounded by endoplasmic reticulum (ER) cisternae. Scale bars: (in $\boldsymbol{B}$ ) $\boldsymbol{A}-\boldsymbol{F}, 10 \mu \mathrm{m}$; (in H) $\boldsymbol{H}, \mathbf{G}, 0.30 \mu \mathrm{m}$; (in $\boldsymbol{J}) \boldsymbol{J}, \boldsymbol{I}, 0.15 \mu \mathrm{m}$. not shown). Within a few days in culture, the cells of positive hybrid clones exhibiting the markers decreased progressively. This instability, which required frequent recloning and recharacterization, explains the much lower levels of the two markers, observed in the hybrid subclone populations with respect to the wt PC12 when analyzed by Western blotting (data not shown).

At the ultrastructural level the wt cells exhibited the well known PC12 phenotype, with numerous DCVs (average diameter $\sim 105 \mathrm{~nm}$ ) (Watanabe et al., 1984) preferentially concentrated in the proximity of the plasma membrane (Fig. $1 G$ ). A fraction of the sections obtained from cells of marker-positive hybrid clones exhibited in contrast only one or a few discrete organelles variable in shape and density, preferentially concentrated in the proximity of the Golgi complex (Fig. 1H). Because of their size (average diameter of $90 \pm 12 \mathrm{~nm}$, measured in 30 DCVs chosen at random) and density, these organelles could be neurosecretory vesicles. To confirm their nature, they were investigated also by immunogold labeling. Figure 1 I shows a cell in which two organelles, one similar to a DCV, the other included in an expansion of a TGN cisterna, exhibit a core strongly immunogold-labeled by the anti-rat $\mathrm{ChgB} \mathrm{mAb}$. Figure $1 J$ shows another hybrid cell with two more clear organelles immunogold-labeled, along their periphery, by the anti-Syt1 mAb. We conclude that in the positive clones a fraction of the cells expresses DCV-like organelles. Moreover, because the ChgB of these organelles is labeled by the rat-specific $\mathrm{mAb}$, it can be encoded only by the PC12 and not by the h-lymphocyte gene.

\section{All marker-positive hybrid clones retained a fragment of human chromosome 11 (11p11-12)}

The study of the hybrid clones positive for the neurosecretion markers was pursued at the cytogenetic level with the aim of characterizing their human chromosome (h-chromosome) profile. Figure 2 shows fluorescence in situ hybridization (FISH) results of typical rat $(A)$ and human $(B)$ metaphase plates, revealed by using as a probe the Alu-PCR products obtained from the DNA of the hybrid F5c clone, used as template (Antonacci et al., 1995). Figure $2 C$ shows a summary of results in various neurosecretionpositive and negative hybrid clones. Positive clones exhibited various patterns of human chromosome fragments including, in all cases, a pericentric fragment of chromosome 11 (11p11-12, arrows in 

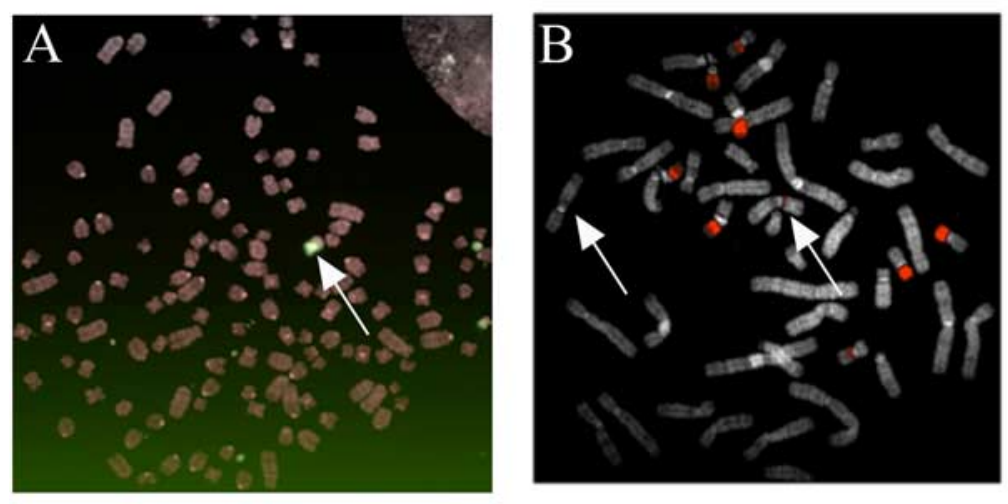

\begin{tabular}{|c|c|c|}
\hline clone & IF & FISH \\
\hline B2b & + & f11p;f20q \\
\hline B10a & + & $16 \mathrm{p} ; \mathrm{f} 20 \mathrm{q} ; \mathrm{f11p} ; \mathrm{f22}$ \\
\hline $\mathrm{F} 4 \mathrm{a}$ & + & 16p;f20q;f22;f9p;f2p;f11p \\
\hline F5c & + & f11p; $16 p ; 19 p ; f 22$ \\
\hline $\mathrm{C} 10 \mathrm{a}$ & +1 & $\mathrm{f} 16 \mathrm{p} ; 19 \mathrm{p} ; \mathrm{f20} \mathrm{q} ; \mathrm{f22} ; \mathrm{f2p} ; \mathrm{f11}$ \\
\hline D8c & + & f16p;19p;f20q;f22;f11p \\
\hline G6c & - & $16 \mathrm{p} ; \mathrm{f} 22$ \\
\hline E5a & - & $19 p ; f 20 q ; f 22 ; 16 p$ \\
\hline E6c & - & f16p;19p;f20q;f22 \\
\hline G4c & - & f16p;19p;f20q;22q \\
\hline
\end{tabular}
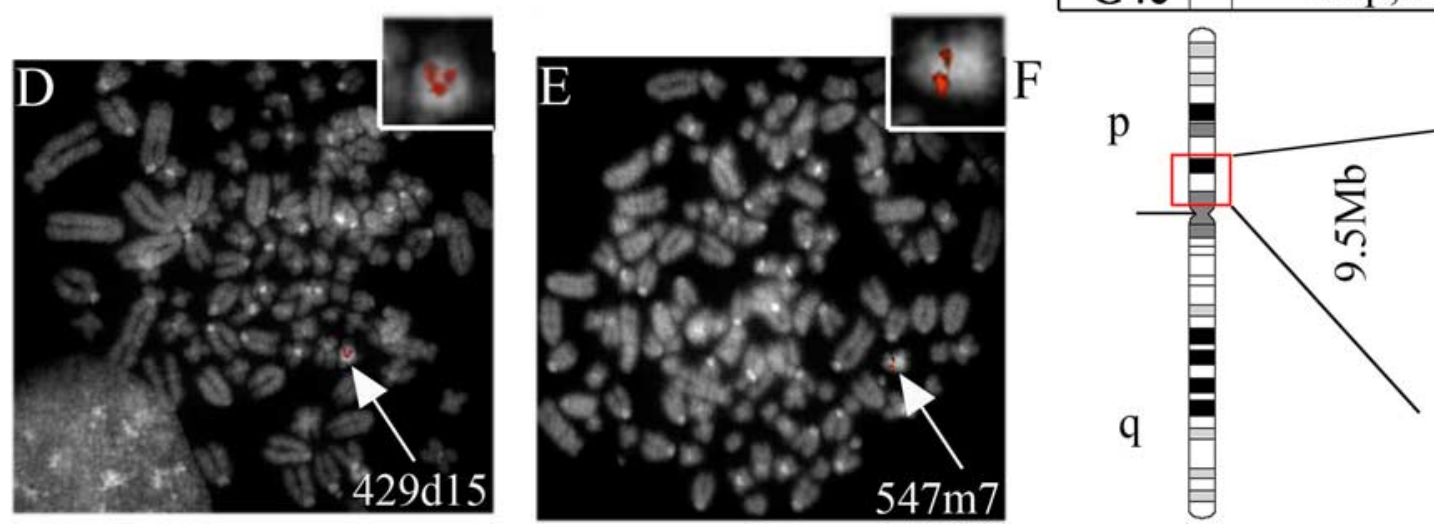

BACs: RP11-18B9 RP11-429d15 RP11-582N4 RP11-705F20 RP11-24413 RP11-574m7 RP11-347E24

Figure 2. FISH and BAC analysis of metaphases. $A, B, A$ rat and a human metaphase, respectively, hybridized using, as a probe, the Alu-PCR products from the DNA of the positive hybrid F5c clone. The arrow in $\boldsymbol{A}$ indicates a h-chromosome fragment present in the hybrid clone, those in $\boldsymbol{B}$ point to the chromosome 11 in a human metaphase. $\boldsymbol{C}$ summarizes the FISH results in 10 clones, 6 neurosecretion marker-positive and 4 negative. Notice that all positive clones exhibited a pericentromeric fragment of the short arm of h-chromosome 11 (arrows in $\boldsymbol{B}$; in bold in $\boldsymbol{C}$ ), which lacked in all negative clones. $\boldsymbol{D}, \boldsymbol{E}$, Two metaphases hybridized using two BACs mapping in the pericentromeric fragment of chromosome 11 (arrows; enlarged in the insets). $\boldsymbol{F}$ lists the most relevant positive (in bold and underlined) and negative BACs used to delimit the fragment of chromosome 11p retained in the marker-positive hybrids (marked in red).

$B)$. In contrast, this fragment was always absent in the negative clones $(C)$.

Various BACs were used as FISH probes to better characterize the extension of the 11p11-12 region. Figure $2 D-F$ summarizes the results in two marker-positive clones. The area between the most centromeric and telomeric positive BACs ( $\sim 9 \mathrm{Mb}$, spanning the region chr11: 40,987,373-50,404,139; UCSC genome browser, March 2006 release) is known to include, together with 13,897 ESTs, also 122 genes. Among these, the BHC80 gene, mapping at chr11:45,910,693-46,099,305, codes for a protein member of BHC, one of the complexes known to mediate the transcription repression of REST. Therefore, the $\mathrm{BHC} 80$ gene was chosen as a candidate implicated in the neurosecretion recovery of the marker-positive hybrid clones.

\section{Expression and distribution of $\mathrm{BHC} 80$}

Expression of the REST and $\mathrm{BHC} 80$ genes was first characterized in PC12, wt and defective, and in hybrid clones. Figure $3 A$ shows that, similar to the level of REST mRNA reported in the PC12-27 defective clone (D'Alessandro et al., 2008), the levels observed in the PC12-Trk, in the positive hybrid clone F5c (Fig. $3 A$ ) and in all other positive PC12-Trk/h-lymphocyte clones assayed (data not shown) were $\sim 80$-fold higher than that of wt PC12. This result excludes fusion with h-lymphocytes to induce a decrease of REST gene expression in the hybrid cells.

The mRNA of $B H C 80$ was approximately threefold higher in wt PC12 than in the defective PC12-Trk (Fig. 3B) and also in the PC12-27 (data not shown). The marker-positive PC12-Trk/h- lymphocyte hybrid clone, F5c, exhibited a significant increase (0.40-fold) over the two defective PC12-Trk and PC12-27, whereas the negative hybrid clone G4c exhibited no change (Fig. $3 B$ ). The increase of the BHC80 mRNA in the positive hybrid clones was due, at least partially, to the expression of the human mRNA, which was lacking in the negative clones (Fig. 3, compare clones $\mathrm{F} 5 \mathrm{C}$ and $\mathrm{G} 4 \mathrm{c}$ ).

In PC12 cells, the BHC80 protein is expressed in two forms, analogous to the splicing forms previously described in mouse and human cells (Hakimi et al., 2002; Iwase et al., 2004). Of these, the smaller BHC80-4 (apparent $\mathrm{Mr} \sim 80 \mathrm{kDa}$ ) was predominant in wt PC12 and in another neurosecretory cell, INS-1E, whereas BHC80-6 (apparent $\mathrm{Mr} \sim 92 \mathrm{kDa}$ ) accounted for almost all the protein expressed by the two defective PC12 clones, by the striated muscle L6 cells (Fig. 3D) and other non-neurosecretory cells (data not shown). Likewise, $\mathrm{BHC} 80-6$ was the form expressed by h-lymphocytes as well as by all hybrid clones, no matter whether negative (data not shown) or positive for neurosecretion markers (F5c and F4a) (Fig. 3E). Quantitatively, in the positive hybrid clones the level of the protein was considerably (4- to 5-fold) higher than in the defective PC12 clones (Fig. 3E, compare F5c and F4a to PC12-Trk), most likely because of their concomitant expression of the human and rat genes. In contrast, in the negative clones the level was as in the defective PC12 (data not shown). Within the cells, BHC80-4 and BHC80-6 were both concentrated in the nucleus, as shown by Western blotting of subcellular fractions (Fig. $3 F$ ) and by immunofluorescence (Fig. 3G). 

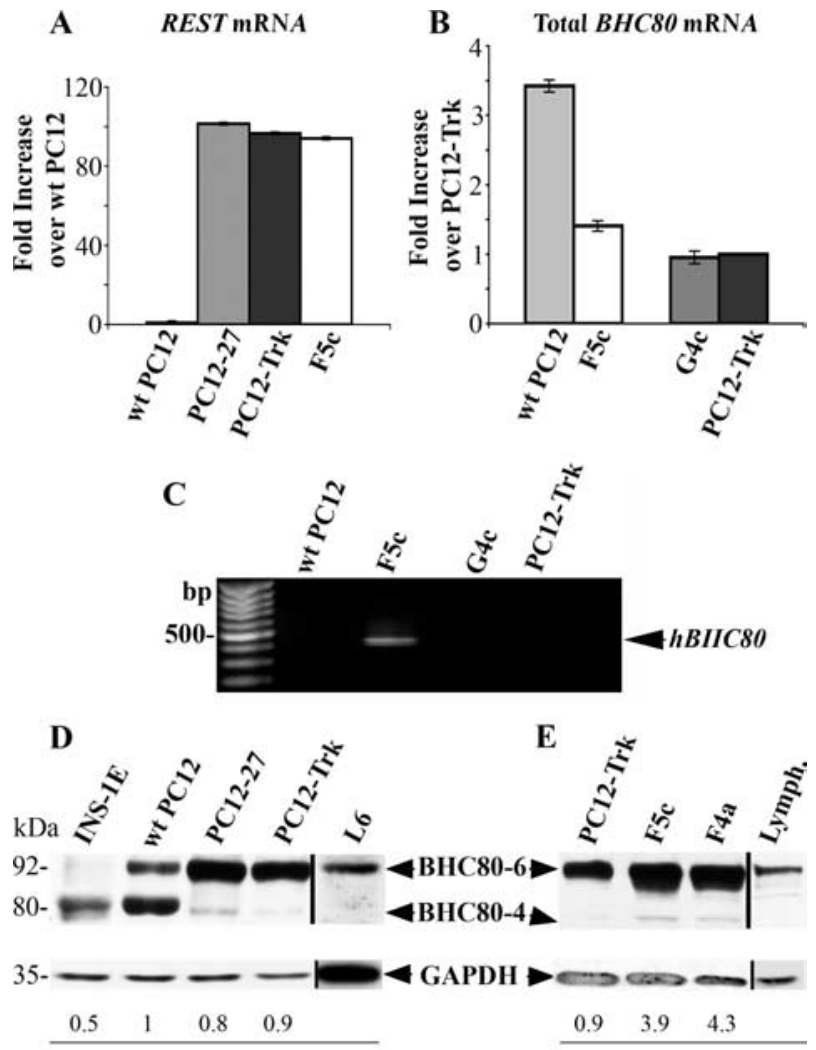

Quantitation of total BHC80 (relative to wt PC12)
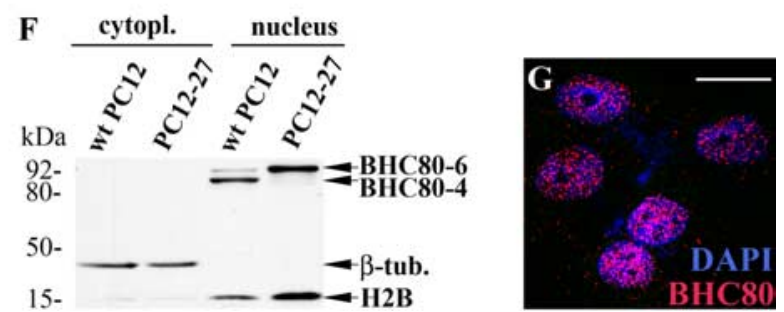

Figure 3. Expression of the $\mathrm{BHC} 80$ gene and distribution of the protein in wt and defective $\mathrm{PC} 12$, PC12-Trk/h-lymphocyte hybrids and other cell types. $A$ shows the much higher levels, with respect to wt $P C 12$, of the REST $m R N A$ in the two defective $P C 12$ clones (PC12-27 and PC12-TrkA), and the persistence of the high REST level in the positive hybrid clone, PC12-Trk/h-lymphocyte $\mathrm{F} 5 \boldsymbol{C} ; \boldsymbol{B}$, the levels of BHC80 mRNA, higher in wt PC12 than in the defective PC12-Trk and in the negative hybrid clone $\mathrm{G} 4 \mathrm{C}$, with the positive clone $\mathrm{F} 5$ c showing a level $40 \%$ higher than the defective clone; $C$, the PCR amplification of a h-BHC80 CDNA fragment, documenting that the $h-B H C 80$ mRNA was expressed in the positive hybrid clone $\mathrm{FC}$, and not in the wt $\mathrm{PC} 12$, the defective $\mathrm{PC12}$-Trk, and also the negative clone $\mathrm{G} 4 \mathrm{c}$. D, E show the expression of the BHC80 protein in various cell types, with predominance of the smaller splicing form, $\mathrm{BHC} 80-4$, in wt $\mathrm{PC} 12$ and also in another neurosecretory cell line, the insulin releasing INS-1Eline $(\boldsymbol{D})$; and predominance of the larger form, $\mathrm{BHC} 80-6$, in the two defective PC12-27 and PC12-Trk (D). In the two positive hybrid clones F5c and F4a $(\boldsymbol{E})$, the predominant form is also $\mathrm{BHC} 80-6$, and its level is distinctly higher than in the cells of origin, PC12-Trk and human lymphocytes (Lymph) (4-5 and over tenfold, respectively). Another non-neurosecretory cell line, the muscle L6 (D), shows also BHC80 - 6, however at levels much lower than those of the PC12 clones. The relative quantitations of total $\mathrm{BHC}$ (80 levels, shown at the bottom of $\boldsymbol{D}, \boldsymbol{E}$, are averages of at least three experiments. $\boldsymbol{F}$ shows subcellular fractionation results documenting that, both in the wt and defective $\mathrm{PC} 12$, BHC80 was localized in the nucleus together with the histone $\mathrm{H} 2 \mathrm{~B}$, and not in the cytoplasm with $\beta$-tubulin ( $\beta$-tub). The localization of $\mathrm{BHC} 80-6$ in PC12-27 cell nuclei, labeled by DAPI, was confirmed also by immunofluorescence $(\boldsymbol{G})$. Scale bar, (in $\boldsymbol{G}) 3 \mu \mathrm{m}$.

\section{Transfection of $\mathrm{BHC} 80 \mathrm{cDNA}$}

The results with PC12-Trk/h-lymphocyte hybrid clones suggested the reappearance of neurosecretion markers to be mediated by the increase of BHC80. To generate tools by which this problem could be directly investigated, experiments of human BHC80 (h-BHC80)-flag cDNA transient transfection were performed in the PC12-27 defective clone, where cDNA transfections are more successful, and in PC12-27/DBD, a PC12-27 clone stably expressing a dominant-negative construct of REST (Bruce et al., 2006; D’Alessandro et al., 2008). In the PC12-27/ DBD cells the REST repression is attenuated, with variable recovery of the neurosecretion gene products that, in the defective PC12, are repressed to a significant (VAMP2, Stxla) or even large (Syp1, Syt1, SNAP25) extent. In contrast, the expression of the ChgB gene, the most sensitive to REST repression, remains inappreciable even in the PC12-27/DBD clone (D'Alessandro et al., 2008).

In view of the existence of the two splicing forms of $\mathrm{BHC} 80$, a series of preliminary experiments were performed to identify possible differential effects on neurosecretion gene expression, using PC12-27 cells transfected with either the h-BHC80-6-flag or the h-BHC80-4-flag cDNAs. However, no differential effects were observed [compare the mRNA levels of supplemental Fig. 1 (available at www.jneurosci.org as supplemental material) to those of Fig. 5A, $B$, concerning the PC12-27 and PC12-27/DBD cells transfected with the h-BHC80-6-flag and the h-BHC80-4flag cDNAs, respectively]. Only the data obtained with one cDNA, that of h-BHC80-4-flag, are therefore reported here. Figure $4 A$ shows that the levels of the REST protein in PC12-27 cells and in their DBD clone were the same and remained almost unchanged when preparations of PC12-27/DBD cells were transfected with different amounts $(0.07,0.4$ and $4 \mu \mathrm{g})$ of h-BHC804-flag cDNA. The BHC80-4 protein, which lacks almost completely in both the PC12-27 (Figs. 3D, F, 4A) and PC12-27/DBD (Fig. $4 A, B$ ), was not increased significantly after transfection of $0.07 \mu \mathrm{g}$ of h-BHC80-4-flag cDNA (Fig. 4A), however it increased progressively after transfection of 0.4 and $4 \mu \mathrm{g}$ (Fig. $4 A$ ). Higher amounts of cDNA could not be used because of the appearance of signs of toxicity in the transfected cells (data not shown). Many subsequent experiments were therefore performed using cells transfected with $4 \mu \mathrm{g}$ of cDNA. Figure $4 B$ shows in PC12-27 and PC12-27/DBD cells the transfected BHC80-4-flag revealed by the anti-flag Ab (left) and the same protein together with the endogenous $\mathrm{BHC} 80-6$ revealed by the anti BHC-80 Ab (right). Notice that in both cell types the levels reached by the transfected and the endogenous proteins were very close (Fig. $4 \mathrm{~B}$ ). The transfected protein (recognized by its flag tag) was found to share the localization of its endogenous counterparts, i.e., to be distributed almost exclusively to the nucleus, as revealed by both subcellular fractionation and immunofluorescence (see the results of PC12-27/DBD cells in Fig. 4C,D).

\section{BHC80 modulates the expression of neurosecretion genes}

Populations of PC12-27 and PC12-27/DBD cells, transiently cotransfected with $4 \mu \mathrm{g}$ of h-BHC80-4-flag together with GFP CDNA, and then enriched by FACS sorting, were used to investigate neurosecretion gene expression. As can be seen in Figure $5 A$, the mRNAs of various such genes, ICA512, VAMP2, Stx1a, $R a b 3 a$, already expressed to a significant extent in the defective PC12-27, were increased considerably after BHC80-4-flag transfection or even brought to the level of wt PC12. The mRNAs lacking in PC12-27, completely or to large extent (ChgB, Syt1, SNAP25, Scg2) were also changed after transfection, however to only small extent (data not shown).

When BHC80-4-flag transfections were made in PC12-27/ DBD cells, that were then enriched by FACS as above, the levels of the neurosecretion mRNAs increased even more than in PC12-27 cells, reaching levels well above or approaching those of 
wt PC12 (Fig. 5B, right). In the same cells, also mRNAs unaffected by BHC80-4-flag transfection in $\mathrm{PC} 12-27$ were considerably increased: that of SNAP25, over fivefold; that of $S y t 1, \sim 3$-fold; that of $S c g 2$ of 0.5 -fold. Even the mRNA of $C h g B$, hardly appreciable in PC12-27/DBD cells (D'Alessandro et al., 2008), became evident after transfection of BHC80-4-flag (Fig. 5B, left).

Transfection of h-BHC80-4-flag cDNA induced clear increases also of neurosecretion proteins, clearly appreciable not in PC12-27 but in PC12-27/DBD cells enriched by FACS sorting. The overall results obtained with $4 \mu \mathrm{g}$ of cDNA are illustrated in part by the Western blot of Figure $5 C$ and in quantitative terms in Figure $5 D$. The proteins that in the PC12-27/DBD cells exhibited already values near to wt PC12, such as VAMP2 (data not shown) and Stxla (Fig. 5C,D, right), were increased only slightly by the BHC80-4-flag transfection. In contrast ICA512, which exhibited a low protein level in PC12-27/ DBD cells (D'Alessandro et al., 2008), was increased considerably, reaching values over the wt level (Fig. 5C,D, right). Syt1, SNAP25 and Syp1, expressed at very low levels in PC12-27/DBD at both the mRNA and protein level, were increased from 2.5 to fourfold (Fig. 5C,D, left). As far as ChgB, the level reached with respect to wt PC12 was low (see also the specific band in Fig. 5C), enough however to reveal (by immunocytochemistry) a population of cytoplasmic puncta (Fig. 5Eb), lacking in the PC12-27/DBD cells (Fig. 5Ea). Interestingly, results obtained by the parallel transfection of the cells with variable amounts of BHC80 - 4-flag cDNA demonstrated that the reappearance of neurosecretion proteins changed depending on the levels of cDNA taken up by the cell.

This dependence was not the same for the various proteins. For example, SNAP25 was appreciably increased already at 0.4 and increased further at $4 \mu \mathrm{g}$ of $\mathrm{cDNA}$, whereas $\mathrm{ChgB}$ required the highest amount of cDNA to become clearly appreciable (Fig. $5 F$ ).

\section{ChIP and immunodepletion analysis of the REST/BHC80} association with RE-1-positive genes

The results reported so far suggested the repression by REST of neurosecretion gene expression to be modulated by BHC80. Whether this effect was caused by the association of the two proteins in the REST repression system or to indirect mechanism(s), was unknown. To investigate the possible association of REST and $\mathrm{BHC} 80$ at single $\mathrm{RE}-1$-containing genes, ChIP experiments were carried out. Cross-linked chromatin preparations from the low REST wt PC12 and the high REST defective PC12-27 cells were immunoprecipitated in parallel with anti-REST and antiBHC80 Abs. The enrichment in the pellet of two well known RE-1-containing genes, i.e., those coding for ChgB and SNAP25, both sensitive to REST repression, however to different extent
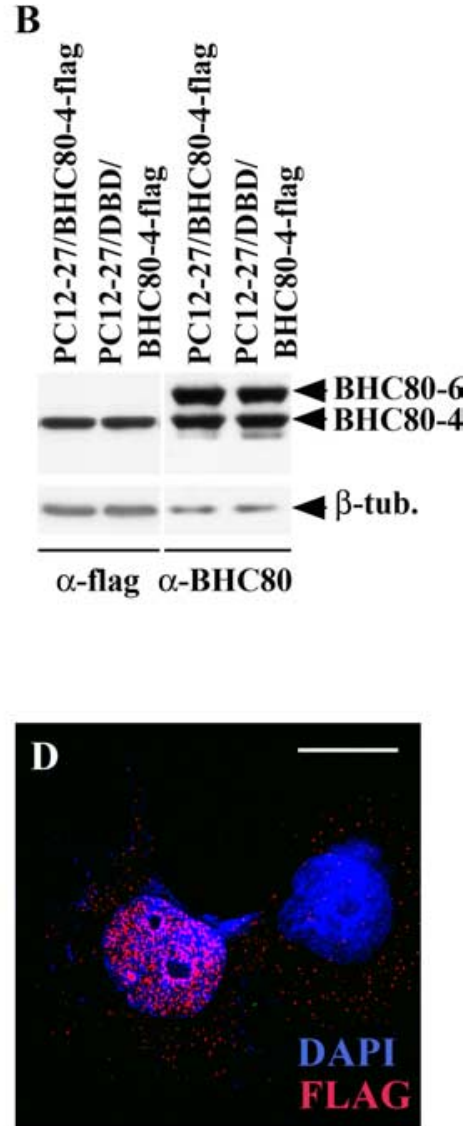

Figure 4. Expression of BHC80 in defective PC12-27 after transfection. $\boldsymbol{A}$, In the transfected PC12-27/DBD cells, the evel of $\mathrm{BHC} 80$ - 4 increase varied depending on the amount of CDNA used: inappreciable in the cells transfected with 0.07 $\mu$, hardly appreciable with $0.4 \mu \mathrm{g}$, clearly visible with $4 \mu \mathrm{g}$. In all the transfected cells the level of REST remains (n) im the same monolayer, only one (lower left) transfected, the other (upper right), negative for the BHC $80-4$-flag. Results such as those of $\boldsymbol{C}, \boldsymbol{D}$ were obtained also with transfected $P(12-27$ (data not shown). The quantitative results shown are means of at least three experiments \pm SD. Scale bar, (in C) $3 \mu \mathrm{m}$.

(D'Alessandro et al., 2008), was evaluated by qPCR. Figure 6, A and $B$, show the ChIP results. In wt PC12 the different sensitivity of the two genes emerged, because the enrichment of the $C h g B$ gene in the chromatin precipitated by the anti-REST Ab was considerable, whereas that of the SNAP25 gene was approximately twofold smaller (Fig. 6A). With the anti-BHC80 Ab the enrichments were not significantly different from those with anti-REST (Fig. 6A). These results were specific because an unrelated $\mathrm{Ab}$ (anti-uPAR) failed to induce any significant precipitation, whereas an unrelated sequence (of NSE) was precipitated neither by the anti-REST nor by the anti-BHC80 and anti-uPAR (Fig. $6 \mathrm{~A}$ ). Moreover, immunodepletion experiments, performed by using the switched Abs to test the anti-REST and anti-BHC80 ChIP supernatants, failed to induce any further precipitation of the two genes (data not shown), indicating that in both cases the fractions bound to REST were mostly coassociated to BHC80 and vice versa.

In the defective PC12-27 cells the results were quite different. The enrichment of both the ChgB and the SNAP25 genes in the 


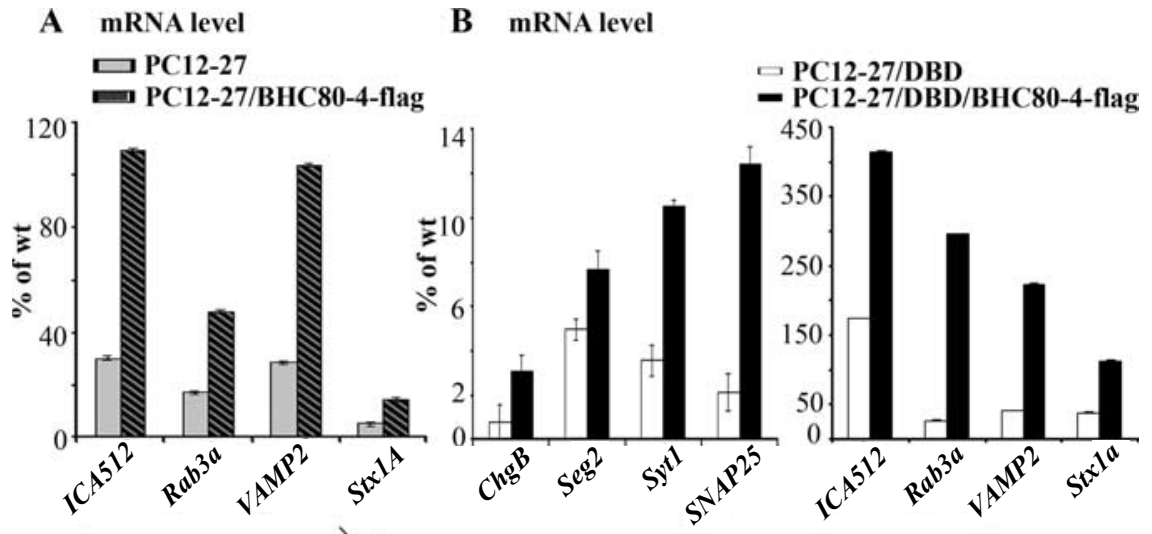

C

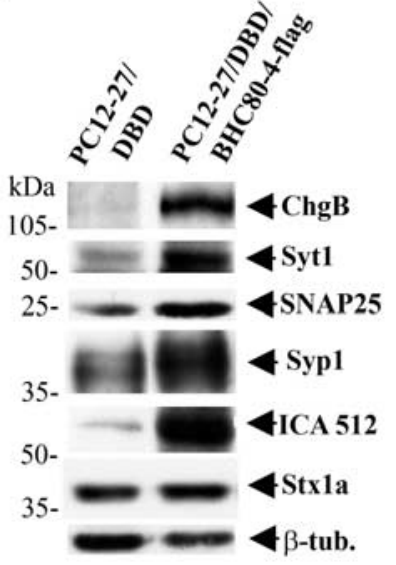

D protein level
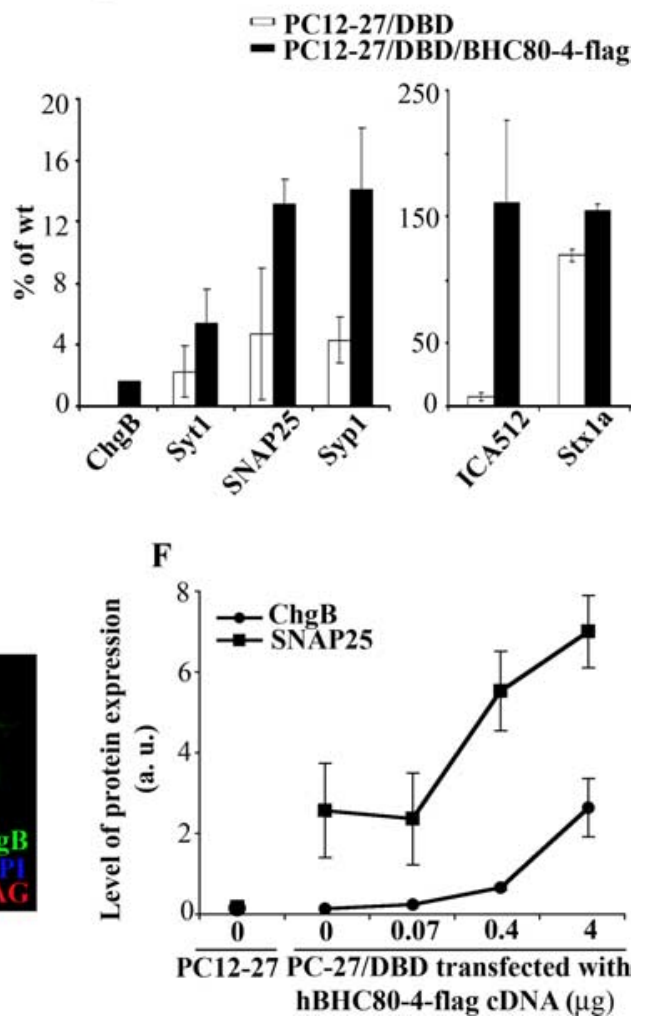

Figure 5. Recovery of neurosecretion markers in PC12-27 and PC12-27/DBD cells cotransfected with the CDNAs of $h-B H C 80-$ 4-flag and GFP. $\boldsymbol{A}, \boldsymbol{B}$, The increases of mRNAs of neurosecretion genes in preparations of PC12-27 and PC12-27/DBD cells cotransfected with of h-BHC80 - 4-flag and GFP CDNAs (4 $\mu \mathrm{g}$ of each) and then enriched by FACS. In PC12-27 (A) the effects of the transfection were variable among the genes. The considerably increased mRNAs shown in the panel are those encoded by genes less sensitive to REST. Minor increases of the other mRNAs are not shown. In PC12-27/DBD cells $(\boldsymbol{B})$, the neurosecretion mRNAs investigated were all increased considerably (from 0.5 - to 10 -fold) by the transfection of BHC $80-4$-flag/GFP. GFP alone was ineffective (data not shown). $\boldsymbol{C}, \boldsymbol{D}$, Significant increases (illustrated by the Western blot of $\boldsymbol{C}$ and summarized by the quantitative data of $\boldsymbol{D}$ ) were induced by the BHC80 transfection of PC12-27/DBD cells also at the protein level. Notice that even ChgB, which in the nontransfected cells was inappreciable, reached small but easily detected levels $(\boldsymbol{C}, \boldsymbol{D})$, sufficient to be revealed by immunofluorescence as discrete cytoplasmic puncta, inappreciable in nontransfected (Ea) and quite evident in the BHC 80 -4-flagpositive cells with nuclei labeled by DAPI $(\boldsymbol{E b})$. $\boldsymbol{F}$, The differential dependence of the expression of two neurosecretion markers, SNAP25 and ChgB, after PC12-27/DBD cell transfection with BHC80 CDNA. SNAP25, already appreciable in the nontransfected PC12-27/DBD cells (see also C, D), was doubled already in the cells transfected with $0.4 \mu \mathrm{g}$ of CDNA and increased further at $4 \mu \mathrm{g}$; $\mathrm{ChgB}$ was clearly appreciable only in the cells transfected with $4 \mu \mathrm{g}$ of CDNA. The quantitative results shown are means of at least three experiments $\pm S D$. The apparent lack of SD on some error bars of $A, B, D$ was caused by the high consistency of the results. Scale bar: (in Ea) Ea, Eb, $3 \mu \mathrm{m}$.

chromatin immunoprecipitated by the anti-REST Ab were much larger (3.6- and almost 5-fold) than those observed in the wt PC12. In contrast, with the anti-BHC80 Ab no appreciable ChIP of the two genes was observed (Fig. 6B). Also in this case the results were specific as shown by the lack of precipitation of the three investigated sequences with the unspecific anti-uPAR antibody and the lack of enrichment of the unrelated NSE gene sequence with the three employed antibodies (Fig. 6B). In the immunodepletion experiments, antiREST induced a considerable enrichment of the two genes from the anti-BHC80 ChIP supernatants, whereas the antiBHC80 Ab immunoprecipitated neither of them from the anti-REST ChIP supernatant (data not shown).

ChIP and immunodepletion experiments were performed also with the chromatin of PC12-27 and PC12-27/DBD cells transfected with $B H C 80 \mathrm{cDNA}$, using the untransfected cells as reference (see supplemental Figs. 2 and 3, available at www. jneurosci.org as supplemental material, which include also the controls with antiuPAR $\mathrm{Ab}$ and the NSE sequence). With PC12-27/DBD cells the results were almost identical to those obtained with PC12-27 cells i.e., large immunoprecipitations of both ChgB and SNAP25 genes induced by the anti-REST antibody (supplemental Figs. 2 and 3 , available at www.jneurosci.org as supplemental material) and no appreciable immunoprecipitation by the anti-BHC80 antibody (Fig. $6 C$ ). When however the PC12-27 and PC12-27/DBD cells were transfected with BHC80, significant immunoprecipitation of the ChgB and SNAP25 (Fig. 6C) genes by the anti-BHC80 antibody reappeared, reaching levels 23 and 50\%, respectively, compared with the wt PC12 (complete data in supplemental Figs. 2 and 3, available at www.jneurosci.org as supplemental material). Together, the ChIP and immunodepletion results document that, in wt PC12 characterized by very low REST, BHC80 and the repressor are associated together to a relatively low fraction of the analyzed $C h g B$ and SNAP25 genes. In contrast, in the PC12-27 and PC12-27/DBD cells, very rich of REST, the possible coassociation of BHC80 to the abundantly associated repressor remains inappreciable by the ChIP technique but reappears, although to a limited extent, when the level of BHC80 was increased after transfection.

\section{Regulated discharge of ChgB from \\ PC12-27/DBD cells transfected with BHC80}

Expression of $\mathrm{ChgB}$ and appearance of ChgB-positive organelles in the cytosol does not demonstrate that regulated neurosecretion has been reestablished after BHC80 transfection in PC12-27/DBD cells. ChgB, in fact, could have been targeted not to its physiological intracellular compartment, that of regulated neurosecretion, but to other organelles, such 

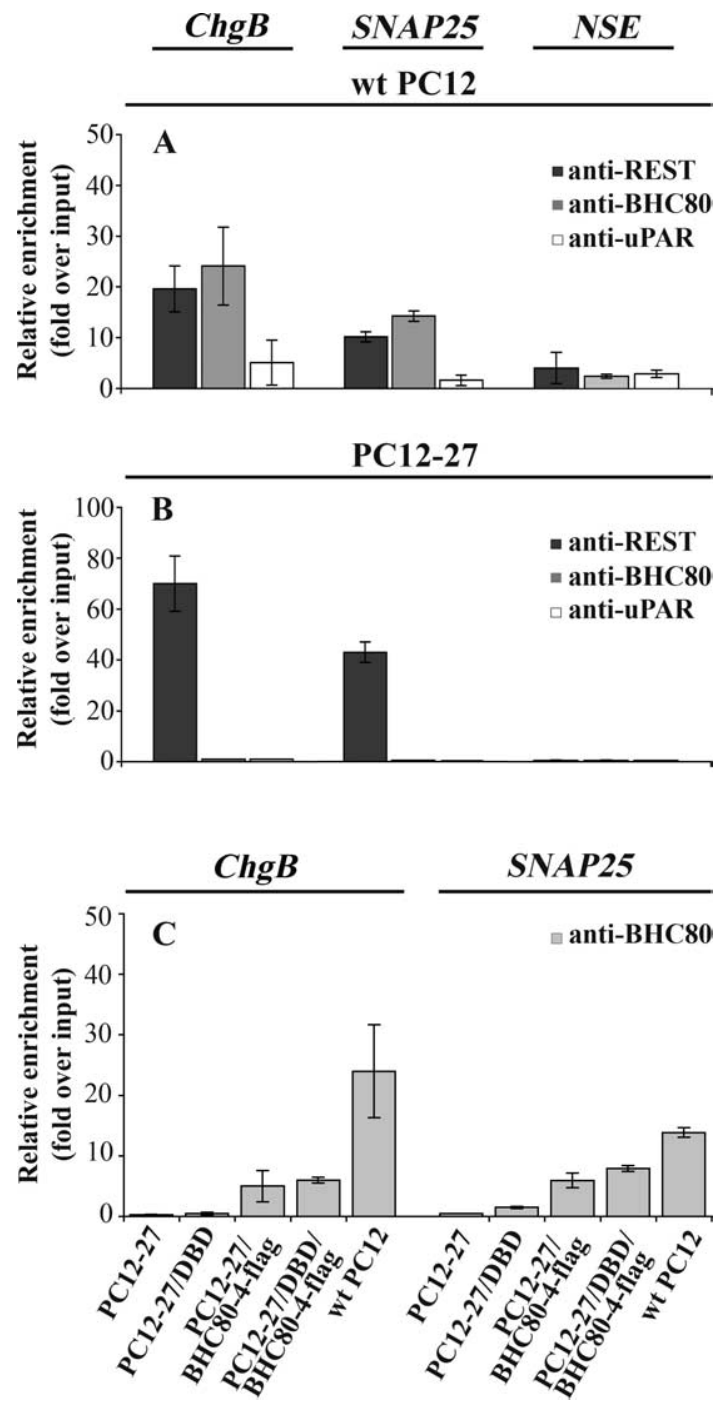

Figure 6. REST and BHC80 interaction with RE-1 genes in wt and defective $P C 12$ cell clones as revealed by ChIP. A refers to wt PC12 and shows the ChgB and SNAP25 gene ChIP results. Notice that immunoprecipitation with both anti-REST and anti-BHC80 induced considerable enrichments of both genes (19.3- and 23.5-fold for the ChgB gene; 9.6- and 14-fold for the SNAP25 gene), much higher than those obtained with the control Ab, anti-uPAR. $A$, right, The lack of significant enrichment of an unrelated region of another gene, that of NSE, with all three Abs. $\boldsymbol{B}$, The ChIP results of the ChgB and SNAP25 genes from the defective PC12-27 cells. Notice that anti-REST induced very large enrichments of the two genes (72.3- and 43.5-fold), whereas anti-BHC80 failed to induce any clearly appreciable precipitation, documenting the large dissociation of the two factors at both the ChgB and SNAP25 genes. The control Ab anti-uPAR and the unrelated region of NSE $(\boldsymbol{B})$ exhibited no appreciable precipitation. $C$ compares the BHC 80 ChIP results of the $C h g B$ and SNAP25 genes from wt and defective PC12 with those obtained in defective $\mathrm{PC} 12$ cells transiently transfected with $\mathrm{BHC} 80$. Notice that $\mathrm{BHC} 80$ transfection induced an appreciable enrichment of the BHC80 associated to the two genes in both PC12-27 and PC12-27/DBD cells, which on the contrary showed no significant difference between them. The complete ChIP and immunodepletion results obtained with the BHC80-transfected cells are shown in supplemental Figs. 2 and 3, available at www.jneurosci.org as supplemental material.

as the vesicles of the constitutive release pathway, which are ubiquitous. To identify the nature of the ChgB-positive organelles and to establish the properties of their possible release, we used two approaches. On the one hand, we investigated the cellular turnover of ChgB. When a secretory protein is sorted to constitutively discharged organelles, its release is rapid even from resting cells $\left(t_{(1 / 2)} \sim 1 \mathrm{~h}\right.$, Malosio et al., 2004; D'Alessandro et al., 2008); when in contrast it is stored in an organelle released by regulated exocytosis, the protein remains stable at rest, and is released only after appropriate cell stimulation. Figure 7 shows that, in PC12-27/DBD cells transfected with BHC80 and incubated in the presence of the protein synthesis blocker, cycloheximide, the level of ChgB, although much lower than that of wt PC12, remained stable for $6 \mathrm{~h}$ (Fig. 7A). This excludes $\mathrm{ChgB}$ to be released constitutively. Release of $30-50 \%$ of the ChgB took place, in contrast, after stimulation of both wt and transfected cells with the $\mathrm{Ca}^{2+}$ ionophore, ionomycin $(2 \mu \mathrm{M}, 15 \mathrm{~min})$ (Fig. 7B). The second approach was immunocytochemical. After DCV exocytosis, part of the discharged ChgB is known to remain for some time attached to the cell surface. This was the case of PC12-27/DBD/BHC80 cells stimulated with ionomycin (Fig. 7 , compare $D$ to the unstimulated PC12-27/DBD/BHC80 cell of $C$ ). We conclude that, in the transfected PC12-27/DBD cells, the organelles in which ChgB is stored are competent for regulated exocytosis, a property typical of authentic DCVs.

\section{Discussion}

This work was initiated to investigate the mechanisms that govern the expression of neurosecretion, starting from its reappearance in the defective, high REST PC12 after heterologous fusion with other cell types (Malosio et al., 1999). To carry out cytogenetic studies, the cells chosen for the generation of a new line of hybrid clones were h-lymphocytes. Our results first excluded the possibility that the recovery of neurosecretion was attributable to a decrease of REST. In fact in all positive hybrid clones the level of the repressor was as high as in the defective PC12. We therefore considered the possibility of the recovery to be due to a negative REST modulation, dependent on a factor encoded by a human gene. Based on the cytogenetic analysis we identified, as a candidate, the gene coding for BHC80, a member of BHC containing a plant homeodomain zinc-finger domain. BHC, a complex that binds the $\mathrm{C}$ terminal domain of REST, has been reported to include various proteins (Co-REST, HDAC1, HDAC2, LSD1) present also in other complexes, together with two specific proteins, BRAF35 and BHC80. Its function is to transduce into epigenetic signals the binding of the repressor to its target genes (Hakimi et al., 2002; Iwase et al., 2004; Shi et al., 2005; Lan et al., 2007).

Inhibition of REST by BHC80 overexpression was not entirely new. In a previous study, transfection of BHC80 had been found to relieve the REST-dependent repression of a RE-1-containing reporter plasmid, an effect abolished by cotransfection of other components of the BHC complex, BRAF35 and HDAC1 (Hakimi et al., 2002). Based on these results, BHC80 had been proposed to operate as a scaffold protein inducing, when over-expressed, the squelching of the BHC complex (Hakimi et al., 2002; Iwase et al., 2004). A more specific mechanism emerged however from more recent studies. BHC80 and another component of the BHC complex, the histone demethylase LSD1, were shown to depend on each other for their association with DNA (Shi et al., 2005; Lan et al., 2007). The functional role of BHC80 remained however debated. In a cell-free system, BHC80 was shown to induce a dose-dependent inhibition of LSD1 (Shi et al. 2005), whereas in HeLa cells it was found to induce a reinforcement of the enzyme activity, possibly mediated by the strengthening of the LSD1 association to its histone H3 target (Lan et al., 2007).

A problem of the studies performed so far to establish the role of $\mathrm{BHC} 80$ depended on the differential expression of the protein in various cells and organs. In particular, BHC80 is 
A
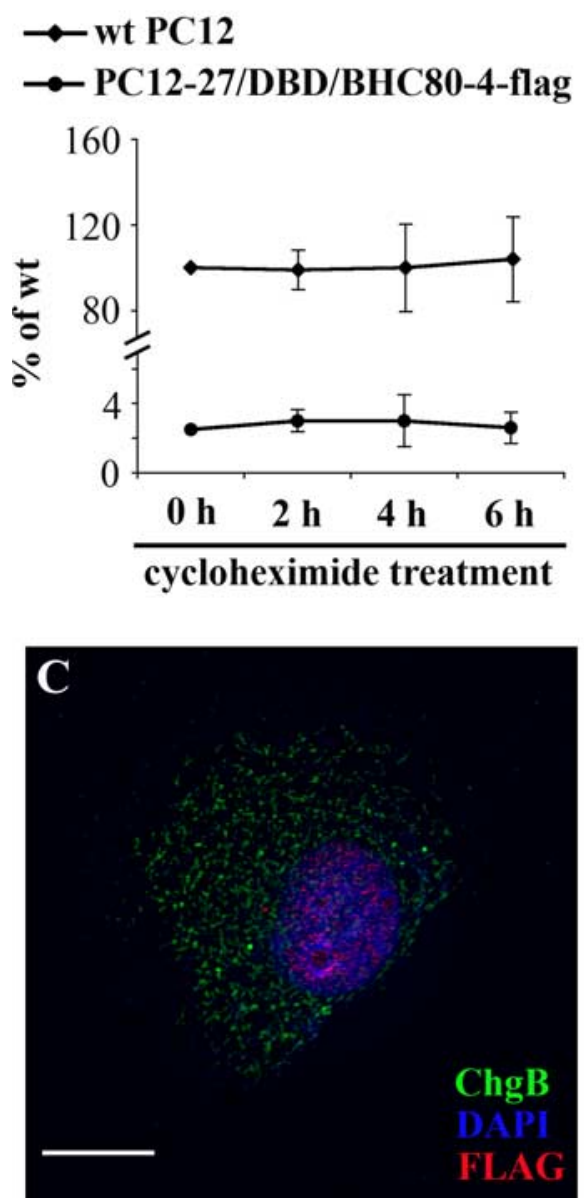

B
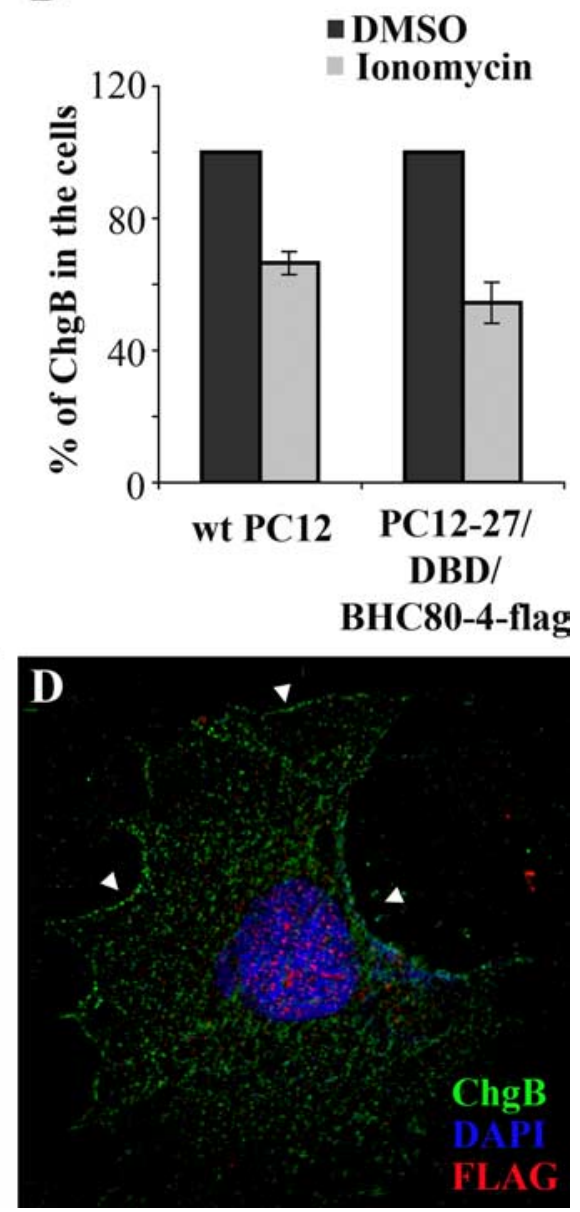

Figure 7. ChgB discharge from $P C 12-27 / D B D$ cells transfected with BHC80 takes place by regulated exocytosis. In $\boldsymbol{A}$, monolayers of wt PC12 and of PC12-27/DBD cells transiently transfected with BHC80 (4 $\mu \mathrm{g}$ of CDNA) in four $6 \mathrm{~cm}$ Petri dishes were incubated in parallel at $37^{\circ} \mathrm{C}$ for up to $6 \mathrm{~h}$ with cycloheximide $(20 \mu \mathrm{g} / \mathrm{ml})$ to block protein synthesis, without applying any stimulation. At the indicated time-points single dishes were removed, the monolayers solubilized and processed by Western blotting. The amounts of $\mathrm{ChgB}$ were established by quantitation of the specific band. Notice that in these resting conditions the ChgB levels of both wt and PC12-27/DBD/BHC80 cells, expressed as percentage of the levels of wt PC12 at 0 time, remained constant in the course of the incubation, i.e., that no constitutive release was appreciable from both cell monolayers. The data shown are means of three experiments \pm SD. $B$, Suspensions in KRH buffer of wt PC12 and of PC12-27/DBD cells transiently transfected with BHC80 as above, incubated for 15 min after addition of the solvent only (DMSO, $1.5 \mu$ l) or the solvent containing the $\mathrm{Ca}^{2+}$ ionophore, ionomycin $(2 \mu \mathrm{m})$. Notice in both cell suspensions the large decrease of ChgB induced by the drug, a regulated release response. The data shown, expressed as percentage of the samples exposed to DMSO, are means of three experiments \pm SD. $C, D$, The ChgB surface immunolabeling of two cells of PC12-27/DBD/BHC80 monolayers, one exposed to DMSO $(\boldsymbol{C})$, the other to ionomycin as in $\boldsymbol{B}$, however, for $2 \mathrm{~min}(\boldsymbol{D})$. Notice that the stimulated cell exhibits a clear label along its surface (arrowheads), whereas the resting cell is almost completely surface-negative. Scale bar: (in $\boldsymbol{C}$ ) $, \boldsymbol{D}, 3 \mu \mathrm{m}$.

high in the brain, where REST is low and many RE-1containing genes are highly expressed, and low in many peripheral organs and non-nerve, REST-rich cells, where RE-1containing genes are repressed (Iwase et al., 2004 and 2006). Because of these profoundly different conditions, it is hard to establish how results obtained in non-nerve cells could be interpreted working in neurons. Here, we have used clones of the nerve cell model, PC12, wt, and defective of neurosecretion. This difference was due to their profoundly different expression of REST (60- to 80-fold higher in the defective clones) (Pance et al., 2006; D'Alessandro et al., 2008). In contrast, the levels of BHC80 were close, with predominance of the small and large splicing forms, BHC $80-4$ and BHC $80-6$, in the wt and defective clones, respectively. Functionally, the two splicing forms appear redundant (Iwase et al., 2004) (see also preliminary data of this study). Therefore, the wt and defective clones were used in parallel to investigate the role of BHC80 in cells exhibiting large differences of REST levels.

Expression of neurosecretion genes, revealed by the reappearance or increase of their mRNAs, especially those encoded by genes least sensitive to REST (VAMP2, ICA512, Rab3a) (D'Alessandro et al., 2008), was observed after transient transfection of defective PC12 with BHC80. In these cells, however, the corresponding proteins and their exocytic organelles, the DCVs, remained inappreciable. In terms of neurosecretion, therefore, the PC12-27 cells transfected with BHC80 might appear different from the hybrids where, despite the very low average levels of neurosecretion proteins, some cells exhibited proteins encoded by genes highly sensitive to REST, such as ChgB and Syt1, as well as DCVs. It should be emphasized, however, that the hybrids, because of the instability of the $\mathrm{h}$-chromosomes, were a mixture of cells positive and negative for the h-BHC80. Most likely, therefore, the hybrid cells exhibiting DCVs and neurosecretory proteins were richer of total $\mathrm{BHC} 80$ compared with the transfected cells which, after FACS selection, were all positive for the exogenous BHC80. The results of $\mathrm{BHC} 80$ transfection changed when the defective PC12 used expressed the dominant negative construct of REST, DBD, known to attenuate the effects of the repressor by competition for RE-1 binding. In these PC12-27/DBD cells, some neurosecretion proteins were present also before BHC80 transfection, however ChgB and DCVs were completely lacking (D'Alessandro et al. 2008). After transfection of BHC80, an apparently complete neurosecretory phenotype reappeared, including DCVs and their regulated exocytosis, analogous, although much less pronounced, to the neurosecretory phenoype of authentic PC12 cells.

Hints about the mechanism by which BHC 80 modulates neurosecretion expression, in wt and defective PC12, emerged from ChIP and chromatin immunodepletion analysis of two genes highly, but differently sensitive to REST repression: highest for ChgB, less pronounced for SNAP25. Unexpectedly, we found that, at the two genes, association of BHC80 was markedly different in wt and defective cells. In wt cells the relatively low REST bound to the genes was largely associated with BHC80; in the defective cells no appreciable BHC80 was detected associated with the much larger REST fraction bound to both genes. The possibility that the change of association had a role in the repression was confirmed by the results obtained with defective PC12 transfected with $\mathrm{BHC} 80$, where a 
clearly appreciable association of $\mathrm{BHC} 80$ with the two analyzed genes was observed. In contrast, expression of the dominant negative REST construct DBD modified neither the lack of BHC80 association observed at the two genes in the defective PC12, nor their association observed after BHC80 transfection. These results confirm that DBD and BHC80 affect REST gene repression by different mechanisms: direct competition for RE-1 binding in the case of DBD (Bruce et al., 2006: D'Alessandro et al., 2008); modulation of its transduction in the case of BHC80.

In conclusion our results, obtained by studying, at both the mRNA/protein and cellular level, the expression of a group of genes specific for a single cell process, neurosecretion, in characterized clones of the neurosecretory PC12 line, provide direct evidence of a modulation by BHC80 of the REST gene repression. A process of this type had been suggested previously, based however on studies cell-free and in non-nerve cells (Hakimi et al., 2002; Iwase et al., 2004; Shi et al., 2005; Lan et al., 2007). Moreover, we show that the association of BHC80 to REST, and its ensuing modulatory effect, depend on the reciprocal levels of expression of the two factors, a finding that appears consistent with the removal of the BHC80 antirepressor effect by exogenous REST, previously reported by Hakimi et al. (2002) in HeLa cells. Our results should be considered together with others that have recently revealed gene repression by REST to be more articulate than the on/off system previously envisaged. In particular, REST complexes mediating the repression of various genes were shown to contain different cofactors, even in the same cell (Greenway et al., 2007; Mulligan et al., 2008). Moreover, the combinatorial regulations of REST with other transcription factors and corepressors were shown to vary in the course of differentiation of stem cells to nerve cells (Sun et al., 2005; Johnson et al., 2008). Our study is the first providing evidence of differences in REST transduction at single genes in clones of the same cell line, however highly different in their REST expression levels. Whether in these cells the expression of BHC80 is constitutive or regulated is unknown. It can however be hypothesized that, in defined conditions, changes of $\mathrm{BHC} 80$ expression contribute to the regulation of REST function. In view of the key role of the repressor and its associated complexes in gene expression, the modulation by BHC80 could have profound effects in cell physiology and possibly also in pathology.

\section{References}

Antonacci R, Marzella R, Finelli P, Lonoce A, Forabosco A, Archidiacono N, Rocchi M (1995) A panel of subchromosomal painting libraries representing over 300 regions of the human genome. Cytogenet Cell Genet 68:25-32.

Ballas N, Mandel G (2005) The many faces of REST oversee epigenetic programming of neuronal genes. Curr Opin Neurobiol 15:500-506.

Borgonovo B, Racchetti G, Malosio M, Benfante R, Podini P, Rosa P, Meldolesi J (1998) Neurosecretion competence, an independently regulated trait of the neurosecretory cell phenotype. J Biol Chem 273:34683-34686.

Borgonovo B, Cocucci E, Racchetti G, Podini P, Bachi A, Meldolesi J (2002) Regulated exocytosis: a novel, widely expressed system. Nat Cell Biol 4:955-962.

Bruce AW, Donaldson IJ, Wood IC, Yerbury SA Sadowski MI, Chapman M, Göttgens B, Buckley NJ (2004) Genome-wide analysis of repressor element-1 silencing transcription factor/neuron restrictive silencing factor (REST/NRSF) target genes. Proc Natl Acad Sci U S A 101:10458-10463.

Bruce AW, Krejcí A, Ooi L, Deuchars J, Wood IC, Dolezal V, Buckley NJ (2006) The transcriptional repressor REST is a critical regulator of the neurosecretory phenotype. J Neurochem 98:1828-1840.

Calderone A, Jover T, Noh KM, Tanaka H, Yokota H, Lin Y, Grooms SY,
Regis R, Bennett MV, Zukin RS (2003) Ischemic insults derepress the gene silencer REST in neurons destined to die. J Neurosci 23:2112-2121.

Chong JA, Tapia-Ramírez J, Kim S, Toledo-Aral JJ, Zheng Y, Boutros MC, Altshuller YM, Frohman MA, Kraner SD, Mandel G (1995) A mammalian silencer protein that restricts sodium channel gene expression to neurons. Cell 80:949-957.

Cocucci E, Racchetti G, Podini P, Rupnik M, Meldolesi J (2004) Enlargeosome, an exocytic vesicle resistant to non ionic detergents, undergoes endocytosis via a non-acidic route. Mol Biol Cell 15:5356-5368.

D’Alessandro R, Klajn A, Stucchi L, Podini P, Malosio ML, Meldolesi J (2008) Expression of the neurosecretory process in PC12 cells is governed by REST. J Neurochem 105:1369-1383.

Dignam JD, Lebowitz RM, Roeder RG (1983) Accurate transcription initiation by RNA polymerase II in a soluble extract from isolated mammalian nuclei. Nucl Acids Res 11:1475-1489.

Ferrai C, Munari D, Luraghi P, Pecciarini L, Cangi MG, Doglioni C, Blasi F, Crippa MP (2007) A transcription-dependent micrococcal nucleaseresistant fragment of the urokinase-type plasminogen activator promoter interacts with the enhancer. J Biol Chem 282:12537-12546.

Formisano L, Noh KM, Miyawaki T, Mashiko T, Bennett MV, Zukin RS (2007) Ischemic insults promote epigenetic reprogramming of mu opioid receptor expression in hippocampal neurons. Proc Natl Acad Sci U S A 104:4170-4175.

Greenway DJ, Street M, Jeffries A, Buckley NJ (2007) RE1 Silencing transcription factor maintains a repressive chromatin environment in embryonic hippocampal neural stem cells. Stem Cells 25:354-363.

Grundschober C, Malosio ML, Astolfi L, Giordano T, Nef P, Meldolesi J (2002) Neurosecretion competence. A comprehensive gene expression program identified in PC12 cells. J Biol Chem 277:36715-36724.

Hakimi MA, Bochar DA, Chenoweth J, Lane WS, Mandel G, Shiekhattar R (2002) A core-BRAF35 complex containing histone deacetylase mediates repression of neuronal-specific genes. Proc Natl Acad Sci U S A 99:7420-7425.

Hakre S, Tussie-Luna MI, Ashworth T, Novina CD, Settleman J, Sharp PA, Roy AL (2006) Opposing functions of TFII-I spliced isoforms in growth factor-induced gene expression. Mol Cell 24:301-308.

Iwase S, Januma A, Miyamoto K, Shono N, Honda A, Yanagisawa J, Baba T (2004) Characterization of BHC80 in BRAF-HDAC complex, involved in neuron-specific gene repression. Biochem Biophys Res Commun 322:601-608.

Iwase S, Shono N, Honda A, Nakanishi T, Kashiwabara S, Takahashi S, Baba $\mathrm{T}$ (2006) A component of BRAF-HDAC complex, BHC80, is required for neonatal survival in mice. FEBS Lett 580:3129-3135.

Johnson DS, Mortazavi A, Myers RM, Wold B (2007) Genome-wide mapping of in vivo protein-DNA interactions. Science 316:1497-1502.

Johnson R, Teh CH, Kunarso G, Wong KY, Srinivasan G, Cooper ML, Volta M, Chan SS, Lipovich L, Pollard SM, Karuturi RK, Wei CL, Buckley NJ, Stanton LW (2008) REST regulates distinct transcriptional networks in embryonic and neural stem cells. PloS Biol 6:e256.

Kaliman P, Canicio J, Shepherd PR, Beeton CA, Testar X, Palacín M, Zorzano A (1998) Insulin-like growth factors require phosphatidylinositol 3-kinase to signal myogenesis: dominnt negative P85 expression blocks differentiation of L6E9 muscle cells. Mol Endocrinol 12:66-77.

Lan F, Collins RE, De Cegli R, Alpatov R, Horton JR, Shi X, Gozani O, Cheng X, Shi Y (2007) Recognition of unmethylated histone H3 lysine 4 links BHC80 to LSD1-mediated gene repression. Nature 448:718-722.

Leoni C, Menegon A, Benfenati F, Toniolo D, Pennuto M, Valtorta F (1999) Neurite extension occurs in the absence of regulated exocytosis in PC12 subclones. Mol Biol Cell 10:2919-2931.

Lichter P, Tang CJ, Call K, Hermanson G, Evans GA, Housman D, Ward DC (1990) High resolution mapping of human chromosome 11 by in situ hybridization with cosmid clones. Science 247:64-69.

Malosio ML, Benfante R, Racchetti G, Borgonovo B, Rosa P, Meldolesi J (1999) Neurosecretory cells without neurosecretion: evidence of an independently regulated trait of the cell phenotype. J Physiol 520:43-52.

Malosio ML, Giordano T, Laslop A, Meldolesi J (2004) Dense-core granules: a specific hallmark of neuronal/neuroendocrine phenotype. J Cell Sci 117:743-749.

Merglen A, Theander S, Rubi B, Chaffard G, Wollheim CB, Maechler P (2004) Glucose sensitivity and metabolism-secretion coupling studied during two-year continuous culture in INS-1E insulinoma cells. Endocrinology 145:667-678. 
Mortazavi A, Leeper Thompson EC, Garcia T, Myers RM, Wold B (2006) Comparative genomics modeling of the NRSF/REST repressor network: from single conserved sites to genome-wide repertoire. Genome Res 16:1208-1221.

Mulligan P, Westbrook TF, Ottinger M, Pavlova N, Chang B, Macia E, Shi YJ, Barretina J, Liu J, Howley PM, Elledge SJ, Shi Y CDYL (2008) Bridges REST and Histone Methyltransferases for Gene Repression and Suppression of Cellular Transformation. Mol Cell 32:718-726.

Otto SJ, McCorkle SR, Hover J, Conaco C, Han JJ, Impey S, Yochum GS, Dunn JJ, Goodman RH, Mandel G (2007) A new binding motif for the transcriptional repressor REST uncovers large gene networks devoted to neuronal functions. J Neurosci 27:6729-6739.

Pance A, Livesey FJ, Jackson AP (2006) A role for the transcriptional repressor REST in maintaining the phenotype of neurosecretory-deficient PC12 cells. J Neurochem 99:1435-1444.

Schoenherr CJ, Anderson DJ (1995) The neuron restrictive silencer (Nrsf)-a coordinate repressor of multiple neuron-specific genes. Science 267:1360-1363.

Shi YJ, Matson C, Lan F, Iwase S, Baba T, Shi Y (2005) Regulation of LSD1 histone demethylase activity by its associated factors. Mol Cell 19:857-864.
Spencer EM, Chandler KE, Haddley K, Howard MR, Hughes D, Belyaev ND, Coulson JM, Stewart JP, Buckley NJ, Kipar A, Walker MC, Quinn JP (2006) Regulation and role of REST and REST4 variants in modulation of gene expression in in vivo and in vitro epilepsy models. Neurobiol Dis 24:41-52.

Sun YM, Greenway DJ, Johnson R, Street M, Belyaev ND, Deuchars J, Bee T, Wilde S, Buckley NJ (2005) Distinct profiles of REST interactions with its target genes at different stages of neuronal development. Mol Biol Cell 16:5630-5638.

Ventura M, Archidiacono N, Rocchi M (2001) Centromere emergence in evolution. Genome Res 11:595-599.

Watanabe O, Torda M, Meldolesi J (1984) The effect of $\alpha$-latrotoxin on the neurosecretory PC12 cell line. Electron microscopy and cytotoxicity studies. Neurosci 10:1011-1024.

Wu J, Xie X (2006) Comparative sequence analysis reveals an intricate network among REST, CREB and miRNA in mediating neuronal gene expression. Genome Biol 7:R85.

Xu YX, Hirose Y, Zhou XZ, Lu KP, Manley JL (2003) Pin1 modulates the structure and function of human RNA polymerase II. Genes Dev 17: 2765-2776. 